RFP-2301

March 29, 1974

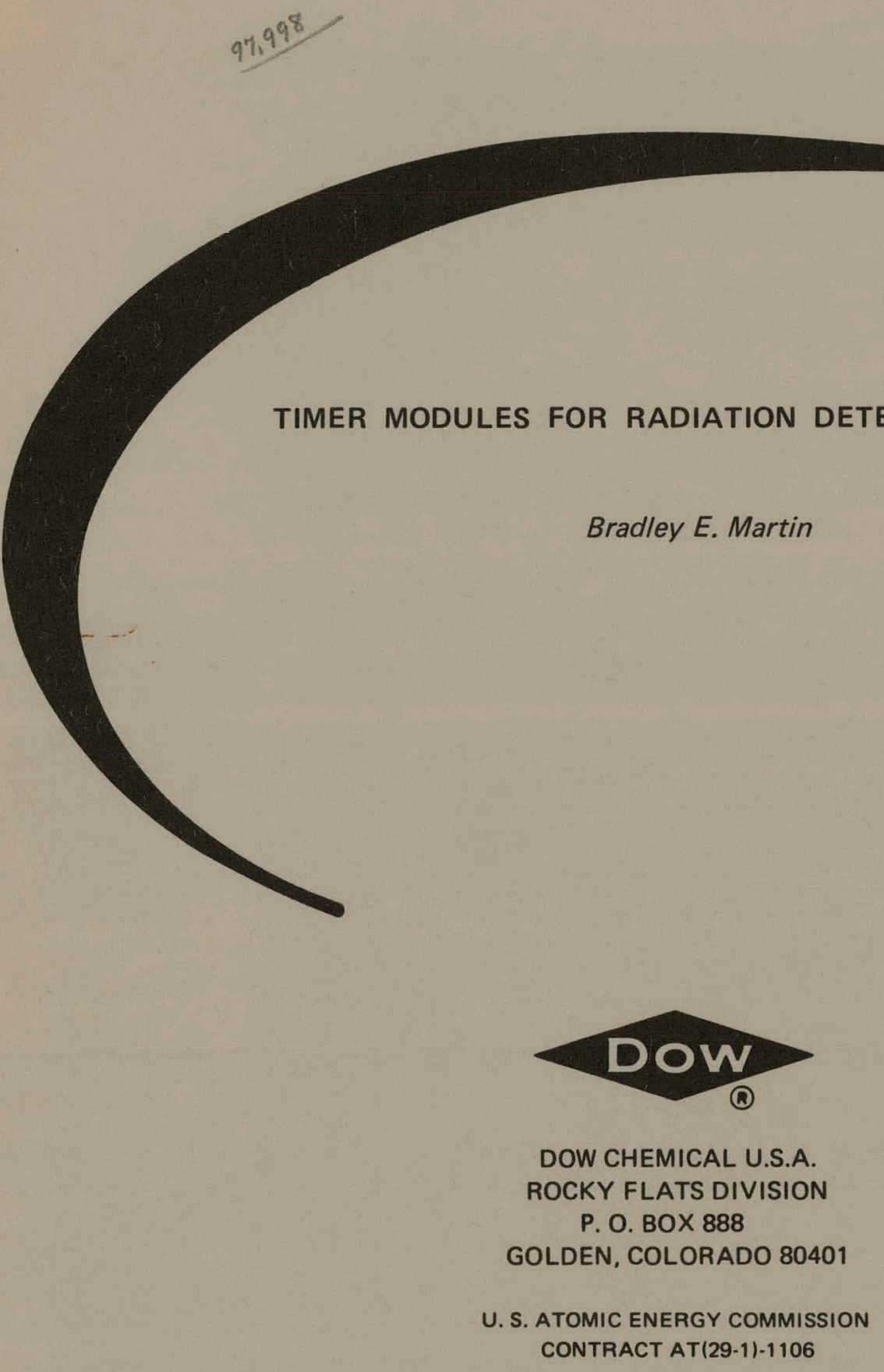




\section{DISCLAIMER}

This report was prepared as an account of work sponsored by an agency of the United States Government. Neither the United States Government nor any agency Thereof, nor any of their employees, makes any warranty, express or implied, or assumes any legal liability or responsibility for the accuracy, completeness, or usefulness of any information, apparatus, product, or process disclosed, or represents that its use would not infringe privately owned rights. Reference herein to any specific commercial product, process, or service by trade name, trademark, manufacturer, or otherwise does not necessarily constitute or imply its endorsement, recommendation, or favoring by the United States Government or any agency thereof. The views and opinions of authors expressed herein do not necessarily state or reflect those of the United States Government or any agency thereof. 


\section{DISCLAIMER}

Portions of this document may be illegible in electronic image products. Images are produced from the best available original document. 


\section{LEGAL NOTICE}

This report was prepared as an account of work sponsored by the United States Government. Neither the United States nor the United States Atumic Energy Commission, nor any of their employees, nor any of their contractors, subcontractors, or their employees, makes any warranty, expressed or implied, or assumes any legal liability or responsibility for the accuracy, completeness or usefulness of any information, apparatus, product or process disclosed, or represents that its use would not infringe privately owned rights.

Printed in the United States of America

Available from the

National Technical Information Service

U. S, Department of Commerce

Springfield, Virginia 22151

Price: Printed Copy $\$ 4.00$ Microfiche $\$ 1.45$ 


\title{
TIMER MODULES FOR RADIATION DETECTION SYSTEMS
}

\author{
- Bradley E. Martin
}

\author{
Product and Health Physics Research
}

\section{ELECTRONICS GROUP}

Modules for Radiation Detection Systems and related items will be grouped in a series of reports beginning with RFP-2300 through RFP-2325. RFP-2300 represents the first report in the series.

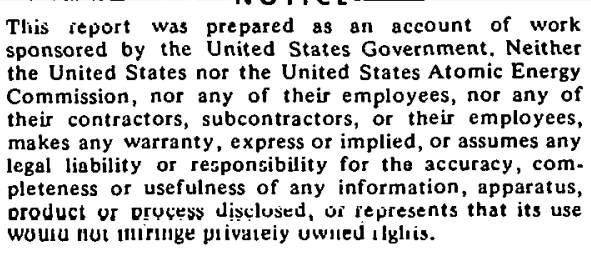

DOW CHEMICAL U.S.A. ROCKY FLATS DIVISION

P. O. BOX 888

GOLDEN, COLORADO 80401

Prepared under Contract AT(29-1)-1106

for the

Alhuquerque Operations Office

U. S. Atomic Energy Commission
SUBJECT DESCRIPTORS

Timer Modules

Alpha Detection Systems

Wound Counting Syetems

Gamma Spectrometers

Electronics

Monitoring Systems

Nuclear Instrumentation BIN

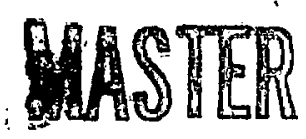


RFP-2301 


\section{CONTENTS}

Abstract $\ldots \ldots \ldots \ldots \ldots \ldots \ldots \ldots \ldots \ldots \ldots \ldots \ldots \ldots \ldots \ldots \ldots \ldots \ldots$

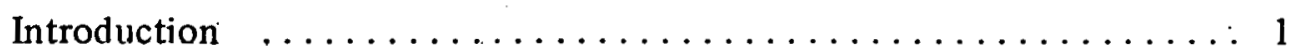

Discussion $\ldots \ldots \ldots \ldots \ldots \ldots \ldots \ldots \ldots \ldots \ldots \ldots \ldots \ldots \ldots \ldots$

Descriptions.$\ldots \ldots \ldots \ldots \ldots \ldots \ldots \ldots \ldots \ldots \ldots \ldots$

Block Diagrams $\ldots \ldots \ldots \ldots \ldots \ldots \ldots \ldots \ldots \ldots \ldots$

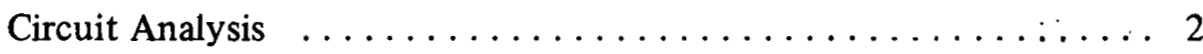

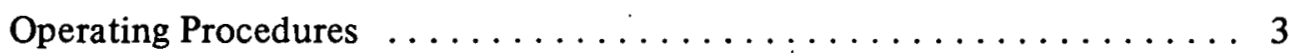

Servicing of Modules $\ldots \ldots \ldots \ldots \ldots \ldots, \ldots \ldots \ldots \ldots, 4$ 
RFP-2301 


\title{
TIMER MODULES FOR RADIATION DETECTION SYSTEMS
}

\author{
Bradley E. Martin
}

\begin{abstract}
Ahstract. In developing radiation detection instrumentation at Rocky Flats, a system concept using plug-in modules was planned. Losses of operational time due to maintenance are drastically reduced as a malfunctioning module can be replaced within minutes. Versatility is another advantage of the modular concept and a particular module can be used in many different system designs. A significant cost savings in system deyelopment can also be realized.
\end{abstract}

Two of the timers described are housed in two-wide Nuclear Instrumentation Bin (NIM-BIN) modules and a third model in a one-wide NIMBIN module. The design uses the latest COS/MOS (complimentary symmetry metal-oxide semiconductor) integrated circuitry, featuring low power, low cost, and high reliability. These modules were developed specifically for radiation detection systems. For clarity, models will be referred to as A, B, and C. Model 24370-21, or $\mathrm{A}$, is used in gross alpha detection systems. Model 27213-21, or B, appears in a medical wound-counter system and the third, Model 27213-23, or C, operates in a gamma spectrometer system. These modules can have application in other related systems as well.

Operational procedures and servicing are included.

\section{INTRODUCTION}

Three timer models are described. Model A (24370-21) was developed for gross alpha-detection systems and Model B (27213-21) was developed for a medical wound-counter system. Model C (27213-23) was developed for a gamma spectrometer system and any of the modules can be used in other related applications.
The timers offer capabilities in collecting data for analysis of levels of radioactive contamination which might occur during plant activities. Under the Health Physics monitoring program at Rocky Flats Plant, concerted efforts are directed towards improvements in safety, state-of-the-art applications, and the reduction of operating costs.

\section{DISCUSSION}

\section{Descriptions:}

The timer modules are accurate timing and control devices and can be used in most data accumulating systems. They provide a reset function, an enable function, and a regulated plus five volts as outputs to external modules. The timing cycle is presettable by means of a thumbwheel switch located on the front panel. Models A (24370-21) and B (27213-21) provide time-interval selections from 00.01 to 99.99 minutes, and Model C (27213-23) is selectable from 0.1 to 9.9 minutes.

Once the desired time has been preset, the timer can be set into operation by depressing the pushbutton switch on the front panel. While the switch is held in, the circuitry generates a lamptest function for checking light-emitting diode (LED) displays within the timer and external modules. When the switch is released, the timer is reset and begins the counting interval. A reset function is also provided for external modules such as a scaler. The timer produces an enable function during the counting interval as a control function for other modules. When the preset time is reached, the timer stops and the enable function terminates. On all models, a lamp inside the pushbutton switch illuminates 
during the counting interval. Model B (27213-21) features an elapsed-time readout.

The complete modules are shown in Figure $1 .^{1}$ The thumbwheel switch snap-fits into the front panel and the timer printed circuit board (PCB) plugs onto the switch. Model C (27213-23) uses an adapter PCB between the timer PCB and the switch. The adapter reduces the preset time from four-to-two decades and allows the circuitry to be mounted in a one-wide module. The elapsed-time readout PCB in Model B (27213-21) mounts on top of the timer PCB (Figures 2, 3, and 4).

Input-output wiring goes to the rear panel connector and the control wiring runs to the pushbutton switch.

The +5 -volt regulator mounts on the rear panel and a test point is provided (Figure 5).

Model B (27213-21) uses a black magic type front panel. The panel is made of red translucent plastic and the back side is painted flat black, with exception of the LED viewing area. The panel appears dark, but the LEDs show through and provide a clearly visible and eyepleasing display.

\section{Block Diagrams:}

Figure 6 shows a block diagram of Model A (24370-21). The +12-volt input is reduced by the regulator to +5 volts, necessary for powering the integrated circuits (IC). The regulator, one of the new three-legged types packaged in a TO-3 case, is capable of handling currents in excess of one ampere. The 5-volt potential is used within the timer module and also fed into the NIM-BIN for use by other modules.

The pushbutton switch, S1, provides the control action for the reset and count-start functions. The switch contains an indicator lamp which illuminates during the timing interval.

\footnotetext{
${ }^{1}$ Figures are included at end of toxt.
}

The thumbwheel switch, comprised of four sections and 16 diodes, makes up a positive $A N D$ gate.

The timer PCB receives 2.5 volts $\mathrm{AC}$ as a 60 -hertz $(\mathrm{Hz})$ reference frequency. When the reset-count switch is activated, the timer PCB counts up the $60-\mathrm{Hz}$ reference and provides the enable output. When the preset time on the thumbwheel switch is reached, the timing interval stops and the enable output terminates.

Figure 7 illustrates Model C (27213-23). It operates the same as Model A (24370-21), except that a two-decade adapter PCB exists between the thumbwheel switch and the timer PCB. This reduces the overall timing capability, however the one-wide module has an advantage where NIM-BIN space is a premium.

Figure 8 shows Model B (27213-21) which operates the same as Model $\mathbf{A}$ with the inclusion of an elapsed time readout assembly. The readout driver PCB senses the binary-coded decimal (BCD) outputs of the timer PCB and converts the $B C D$ to seven-segment outputs. The readout PCB contains four MAN-64A seven segment LED displays.

\section{Circuit Analysis:}

In Figure 9, a schematic diagram of Model A (24370-21), the ICs A1 and A2 form a control logic circuit. The ICs, A3 and A4, are divide-bysix counters and $A 5$ through $A 8$ are decado (divide-by-ten) counters. The positive $A N D$ gate formed by the thumbwheel switch senses the BCD outputs of the decade counters at J1 through J4.

The control logic circuit is triggered by the pushbutton switch, S1, noted in Figure 6. As the pushbutton switch is depressed, R3 pulls the reset line high ( +5 volts) and the counters reset to zero. The counters, A5 through A8, use a ground on the jam inputs, with the reset applied to the preset enable input to force-reset 
the counters to zero. The switch forces to ground Pin 8 of A2. The circuit of A2 forms a switch contact debounce and control flip-flop. Pins 2, 10 , and 13 of A2 and Pins 9, 11, and 14 of A1 all go high. This causes Pins 10,12, and 15 of A1 to go low (zero volts) and produce the enable output. Pin 1 of $\mathrm{A} 2$ receives the $60-\mathrm{Hz}$ input and passes it to Pin 14 of A3, the input of the counters. Counting will not yet begin, as the reset line, still high, holds the counters in the reset condition.

When the pushbutton switch is released, Pins 8 and 12 of $\mathrm{A} 2$ go high and Pin 2 of A1 goes low allowing Q1 to conduct and turn on the lamp. The reset is removed from the counters which will begin counting the $60-\mathrm{Hz}$ reference.

The timing interval, then in progress, will continue until all inputs of the diode positive $A N D$ gate formed by the thumbwheel switch are satisfied.

For example, suppose 1.5 minutes are selected on the thumbwheel switch. The diodes connected to Pins 2 and 11 of $\mathrm{J} 3$ and Pin 2 of $\mathrm{J} 2$ will form the gate. All other diodes are disconnected from the gate because of the mechanical construction of the thumbwheel switch. At a count of 1.5 minutes, these inputs will be high allowing the output of the gate to be pulled high by R4. The output is common at Pin 8 of $\mathrm{J} 1$ through $\mathrm{J} 4$. The high from the gate output is applied to Pin 7 of A1 causing Pin 6 of A2 to go low and reset the flip-flop of A2. Pin 10 of A2 goes low driving Pin 11 of A2 high which shuts off Q1 and turns off the lamp. Pins 10, 12, and 15 of A1 go high changing the enable output to a disable. Pin 2 of A2 goes low and prevents A2 from passing the $60-\mathrm{Hz}$ reference frequency to the counters. The timing interval, then complete, will remain in this state until the pushbutton switch is pressed.

Capacitors $\mathrm{C} 1$ and $\mathrm{C} 2$ provide proper filtering for COS/MOS circuitry.

Figure 10 shows Model C (27213-23). The circuit operates the same as Model A. The decade timer adapter PCB senses the BCD outputs from A6 and $\mathrm{A} 7$ and couples them to the thumbwheel switch. This limits the timing capability to twodecades. The J5 connector of the timer PCB plugs into the adapter and the adapter plugs onto the thumbwheel switch.

Figure 11 shows a schematic diagram of the readout driver PCB and the readout PCB, used in Model B (27213-21). Plug 5 of the readout driver PCB plugs onto J5 of the timer PCB. The readout driver and the readout $\mathrm{PCBs}$ are permanently affixed together by a right angle connector. The BCD outputs from the timer PCB are sensed by $\mathrm{A} 1$ through $\mathrm{A} 4$ and converted to seven-segment outputs which will drive the MAN-64A displays on the readout PCB. Resistor R1 limits the current to the decimal point display. Diode D1 is an isolation diode for the lamp test circuit and $\mathrm{C} 1$ provides decoupling.

Figure 12 gives component layouts and switch data for the PCBs used in the timers. Component layout for Model B (27213-21) is given in Figure 13(a), readout components in 13(b), and readout driver components in 13(c).

Adapter component layout for Model C (27213-23) is given in Figure 14.

\section{OPERATING PROCEDURES}

The following procedures and requirements are recommended for use with the timer models described, Models A, B, and C.

1. Plug timer module in NIM-BIN.

a. Power requirements :
(1) +12 volts DC, Pin 16
(2) 2.5 volts $\mathrm{AC}$, Pin 26

2. Turn on NIM-BIN power.

3. Set the thumbwheel switch for desired time.

4. Timer is ready for operation. Press pushbutton switch to operate. 


\section{SERVICING OF MODULES}

The chart has been included as a troubleshooting guide to assist in the performance of unscheduled maintenance.

\begin{tabular}{|c|c|}
\hline Problem & Cause \\
\hline No +5 volts $\mathrm{DC}$ & $\begin{array}{l}\text { 1. No }+12 \text { volts DC } \\
\text { input } \\
\text { 2. Short on }+5 \text { volt } \\
\text { line } \\
\text { 3. Faulty regulator }\end{array}$ \\
\hline $\begin{array}{l}\text { Does not Time } \\
\text { No Enable } \\
\text { No lamp }\end{array}$ & $\begin{array}{l}\text { 1. No }+5 \text { volts DC } \\
\text { input } \\
\text { 2. Faulty A2 } \\
\text { 3. Faulty A1 }\end{array}$ \\
\hline
\end{tabular}

Problem

Does not Time

Lamp and Enable OK

No Enable output

No Lamp indication

Times-Out incorrectly, or Does not Time-Out at all
Cause

1. Faulty $\mathrm{A} 2$

2. No 60-hertz input

1. Short on enable line

2. Faulty A1

1. Bulb burned out

2. Faulty Q1

3. Faulty A1

1. Faulty Counter (A3 through A8)

2. Faulty diode on thumbwheel switch

FIGURE 1. Front View of Timer Modules.

17698-10

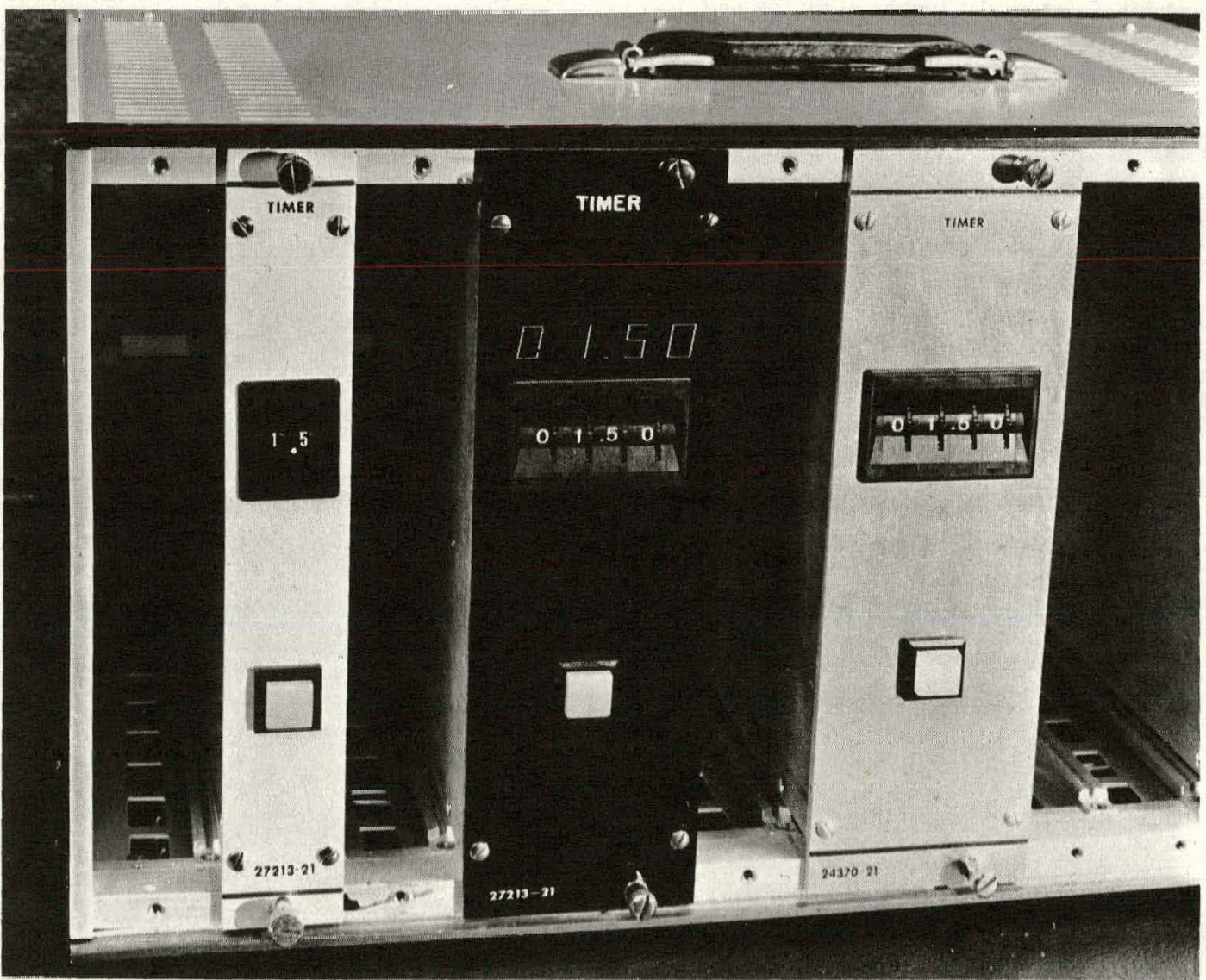




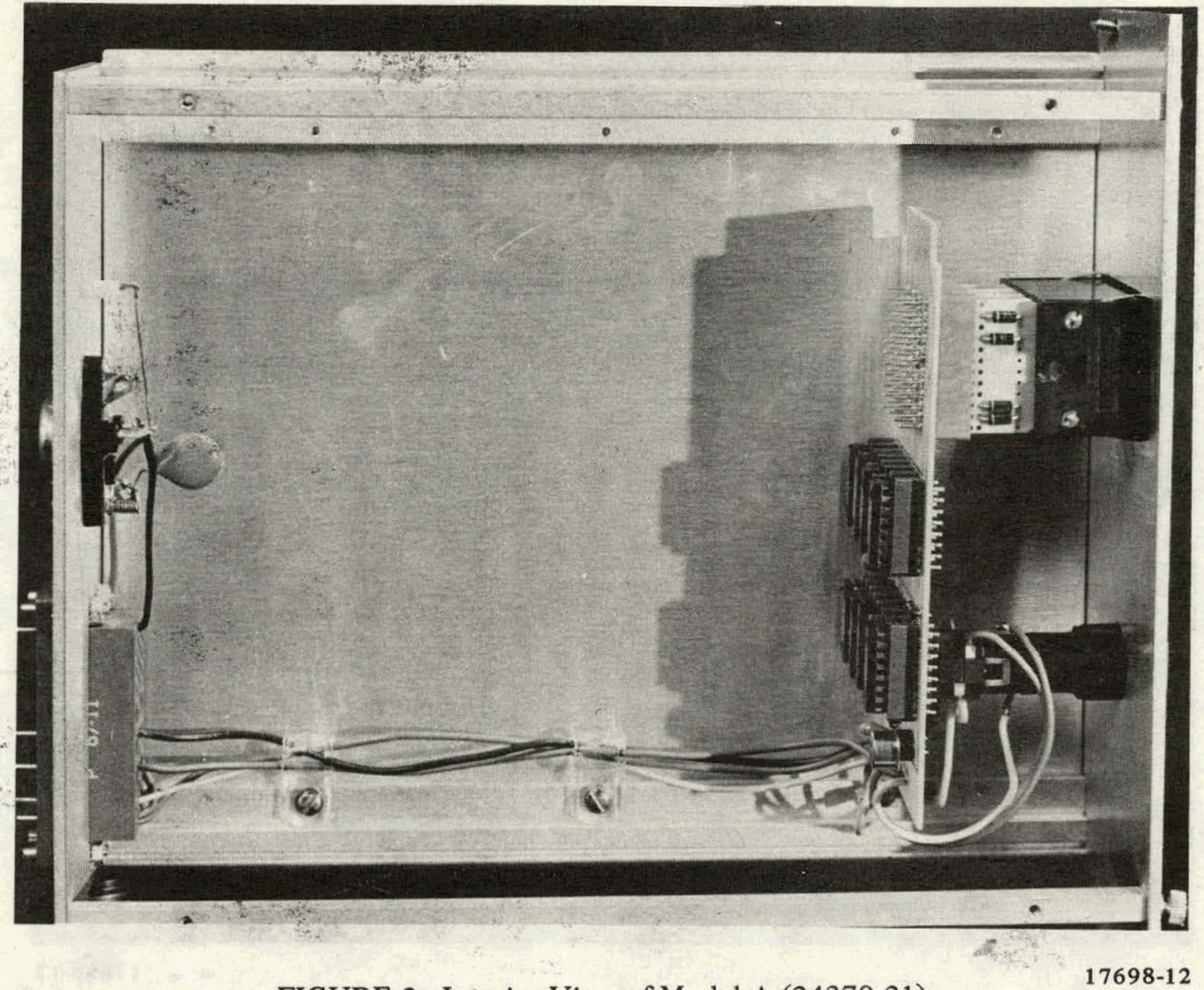

FIGURE 2. Interior View of Model A (24370-21).

FIGURE 3. Interior View of Model B (27213-21).

17698-1

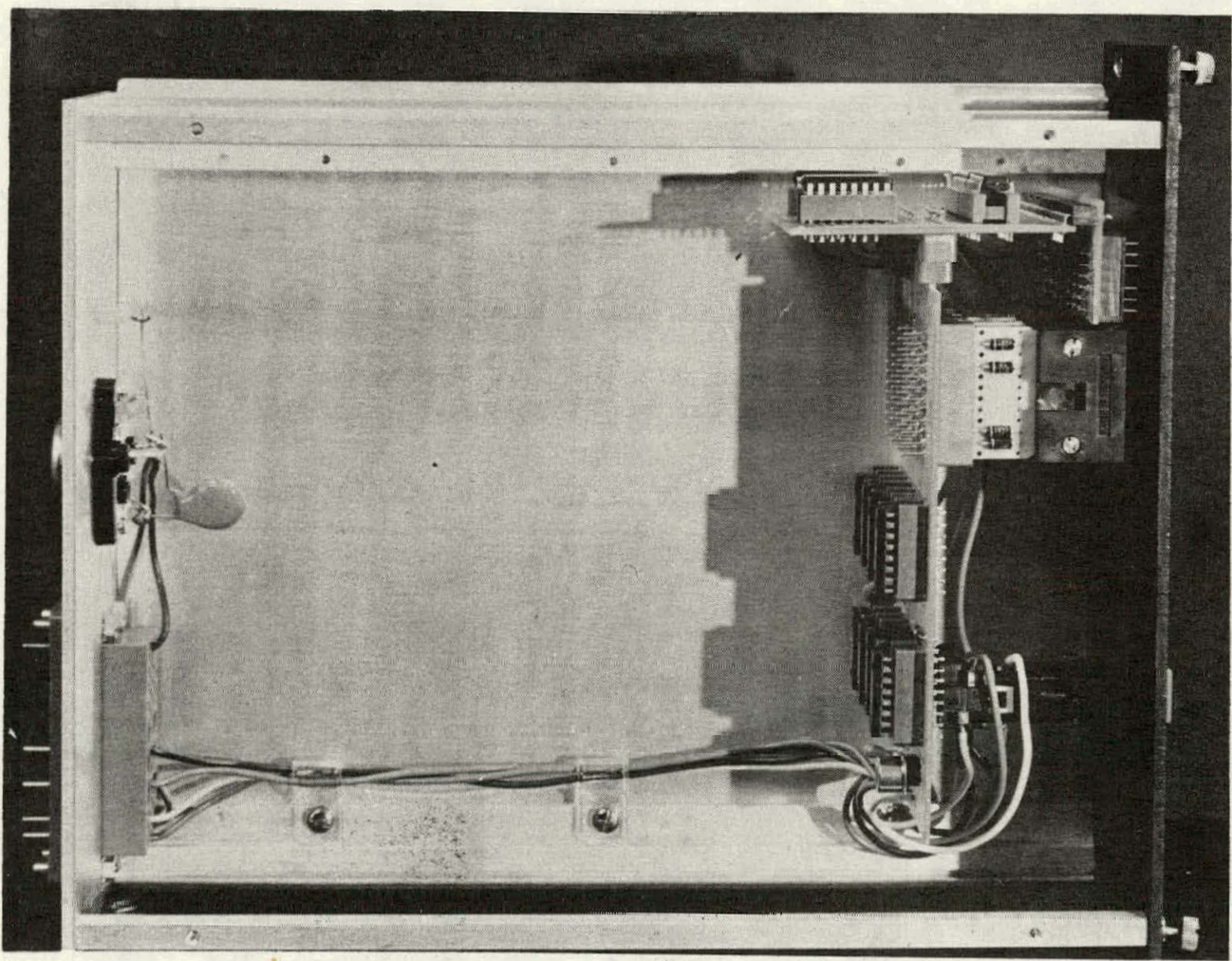


RFP-2301

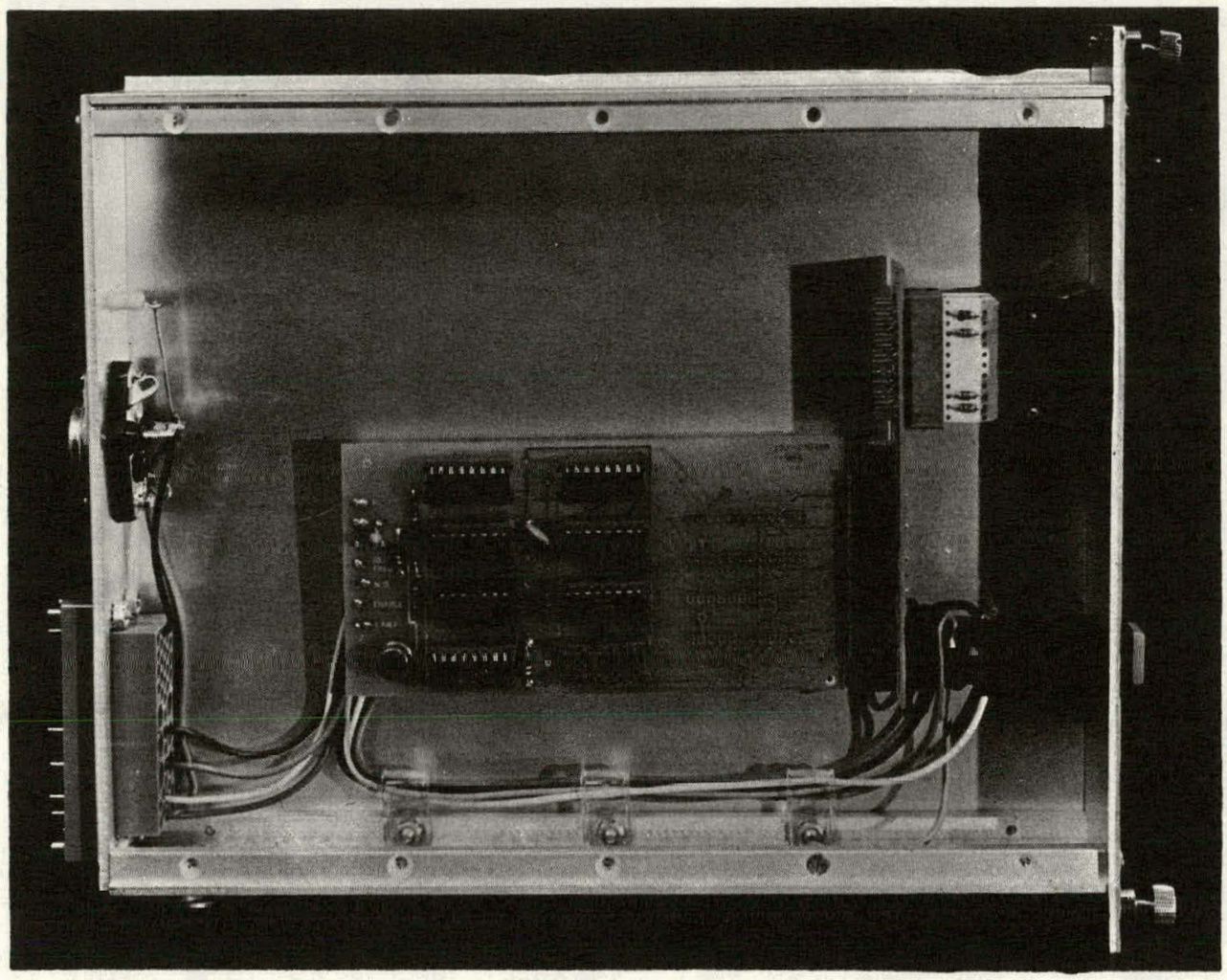

FIGURE 4. Interior View of Model C (27213-23).

FIGURE 5, Rear Viow of Timer Modules.

17698-4

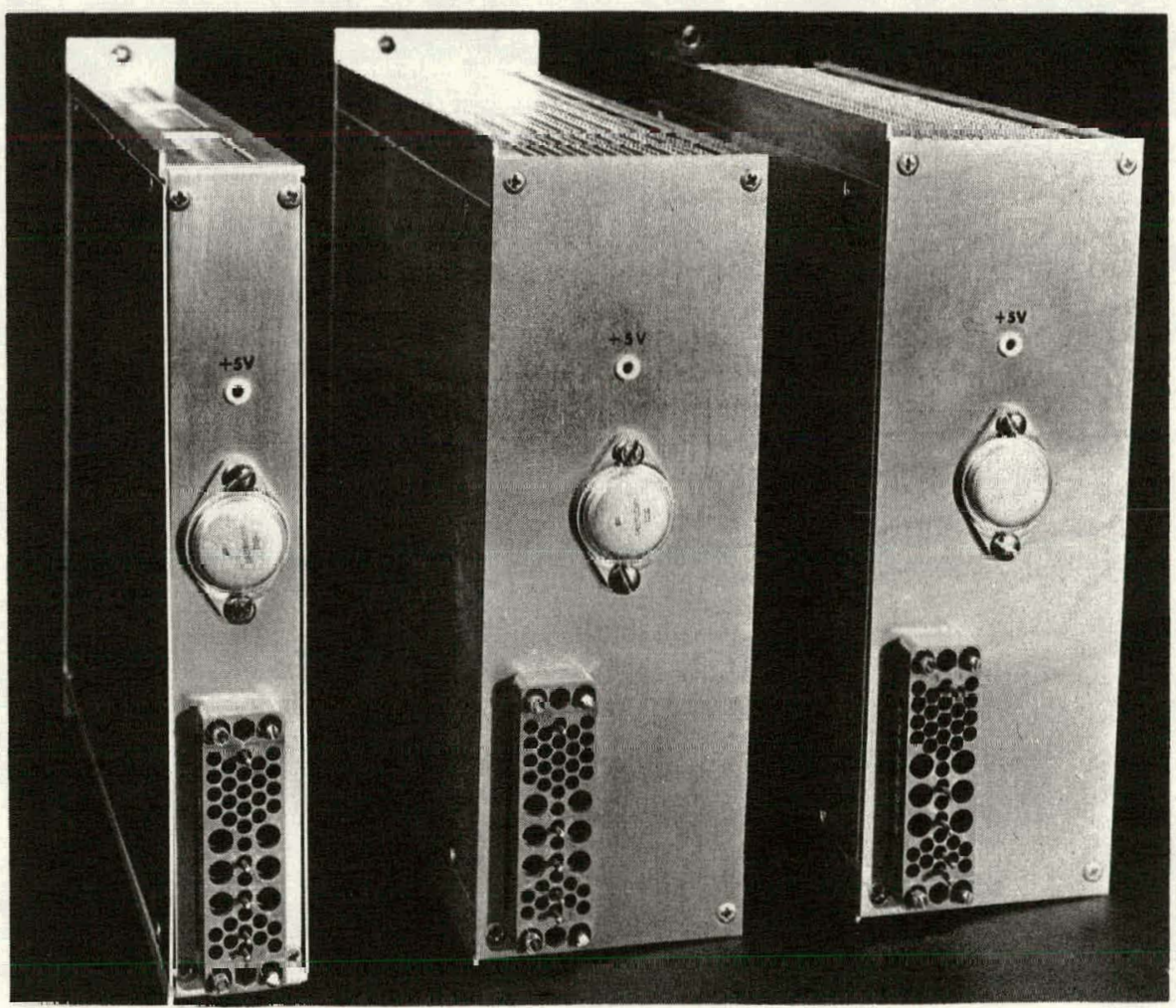




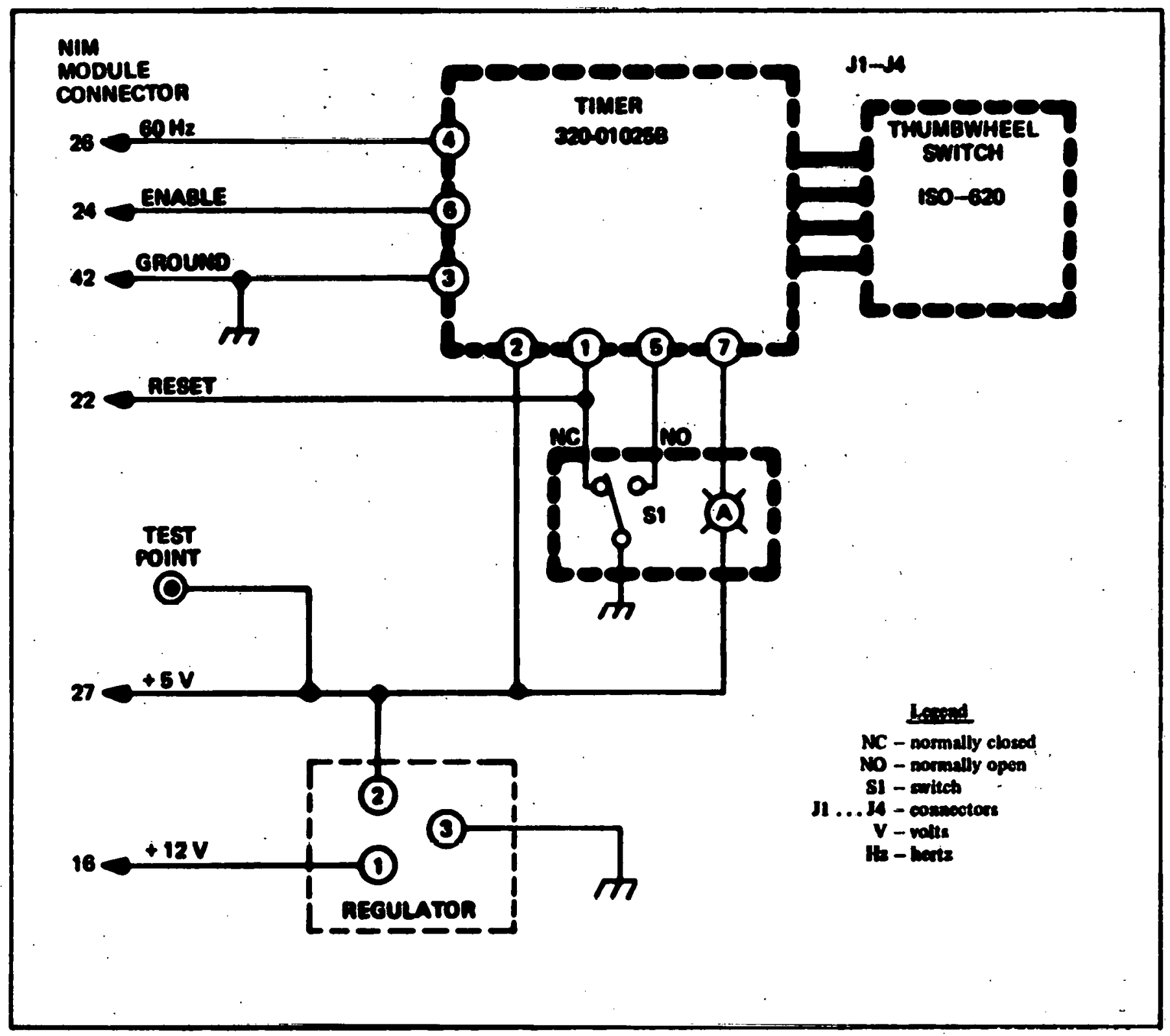

FicUlie 6. Thror Bbok Dbaram, Modd A (24370-21). 
RFP-2301

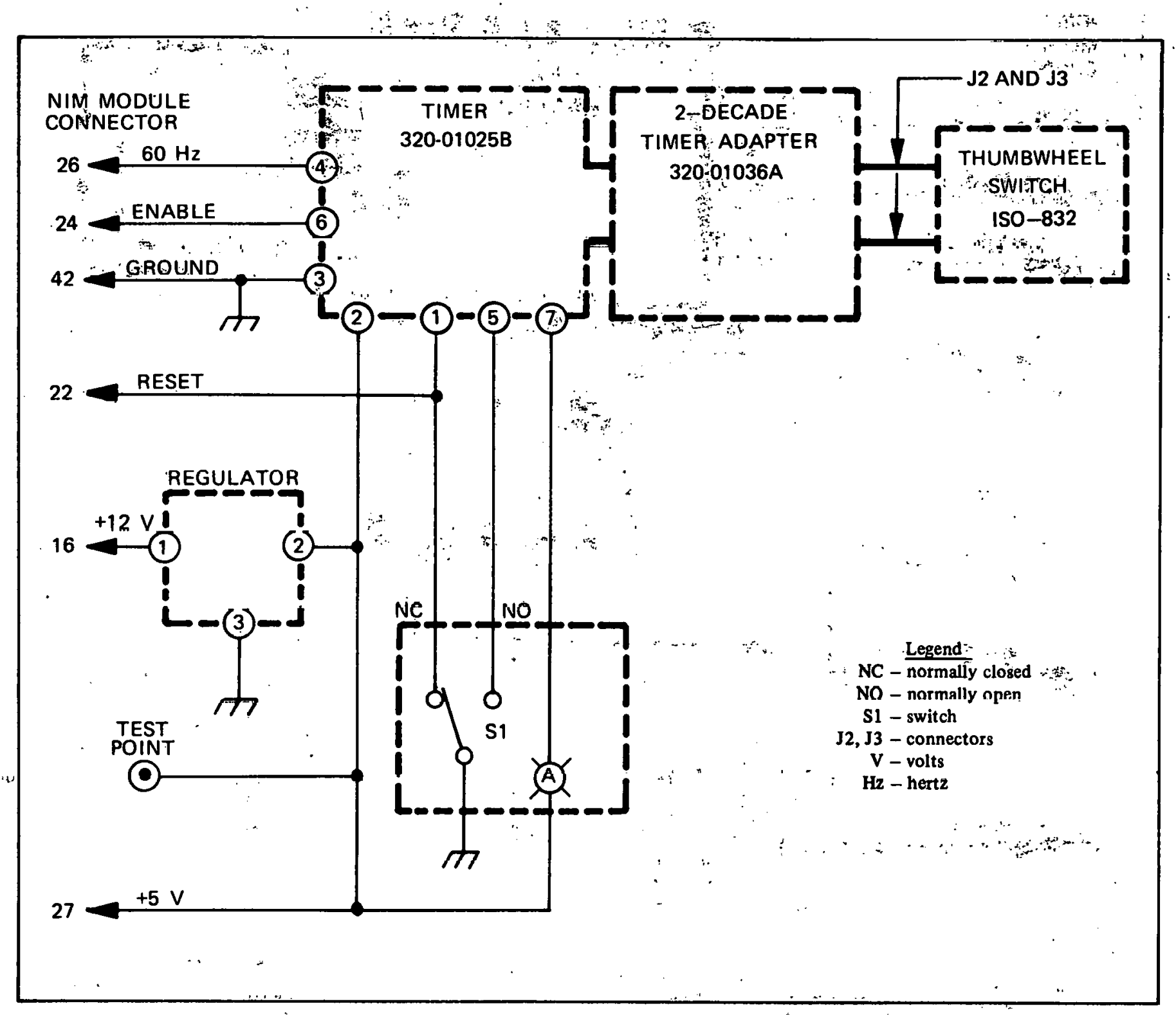

FICURE 7. Two-Doende Timer Block Diagram, Model C (27213-23). 


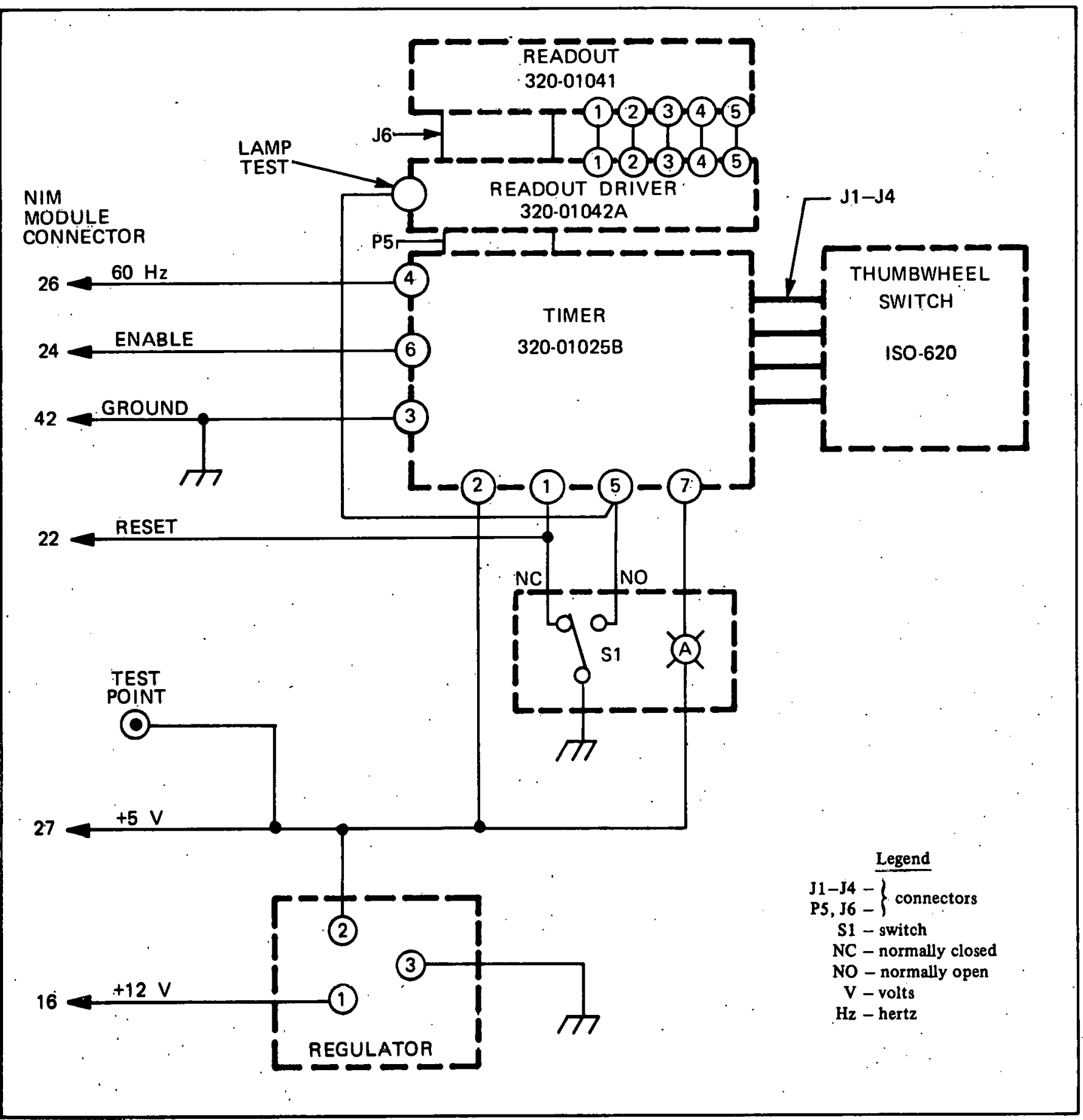

FIGURE 8. Timer Block Diagram, Model B (27213-21). 


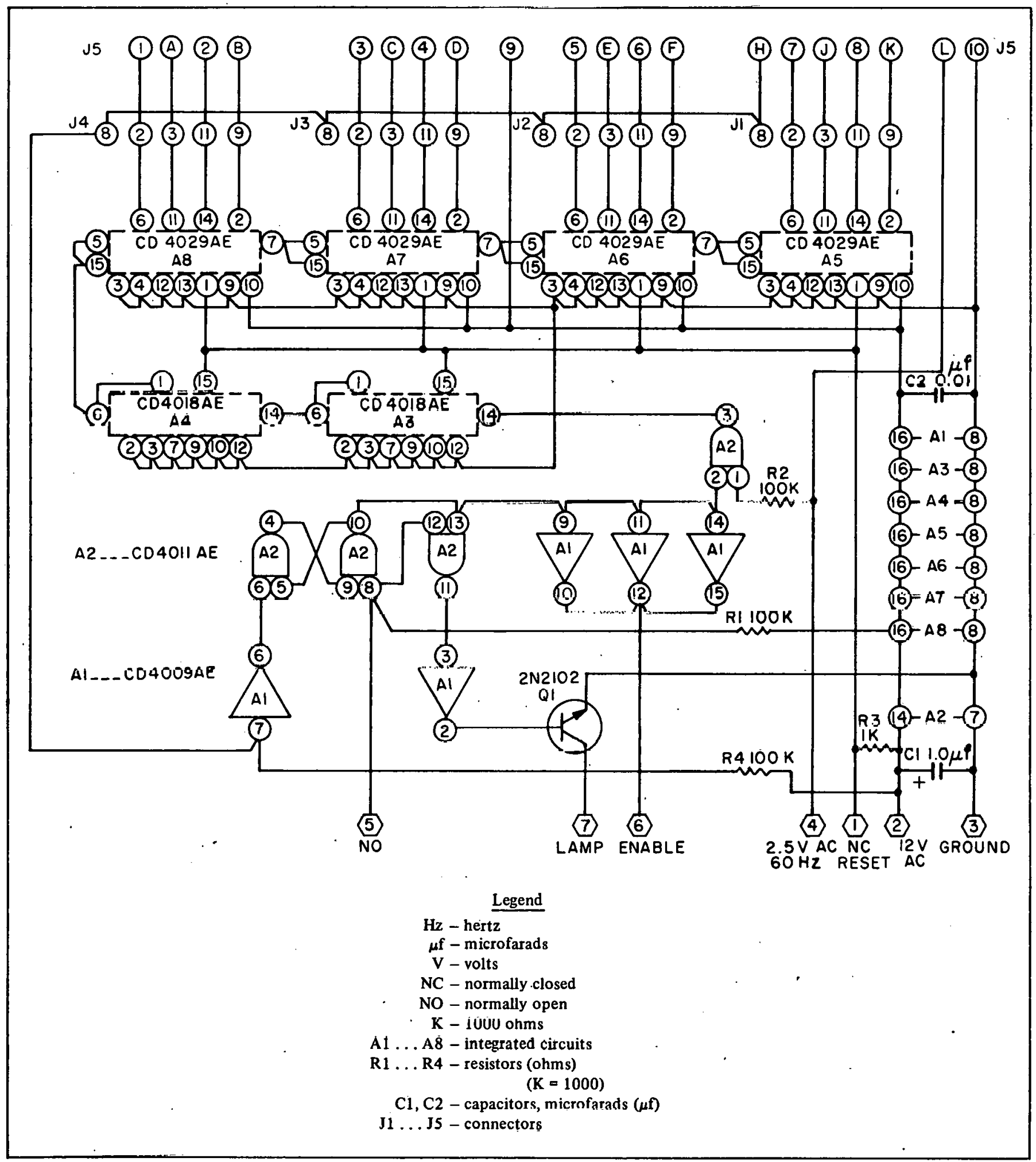

FIGURE 9. Timer Printed Circuit Board, Model A (24370-21). 
RFP-2301

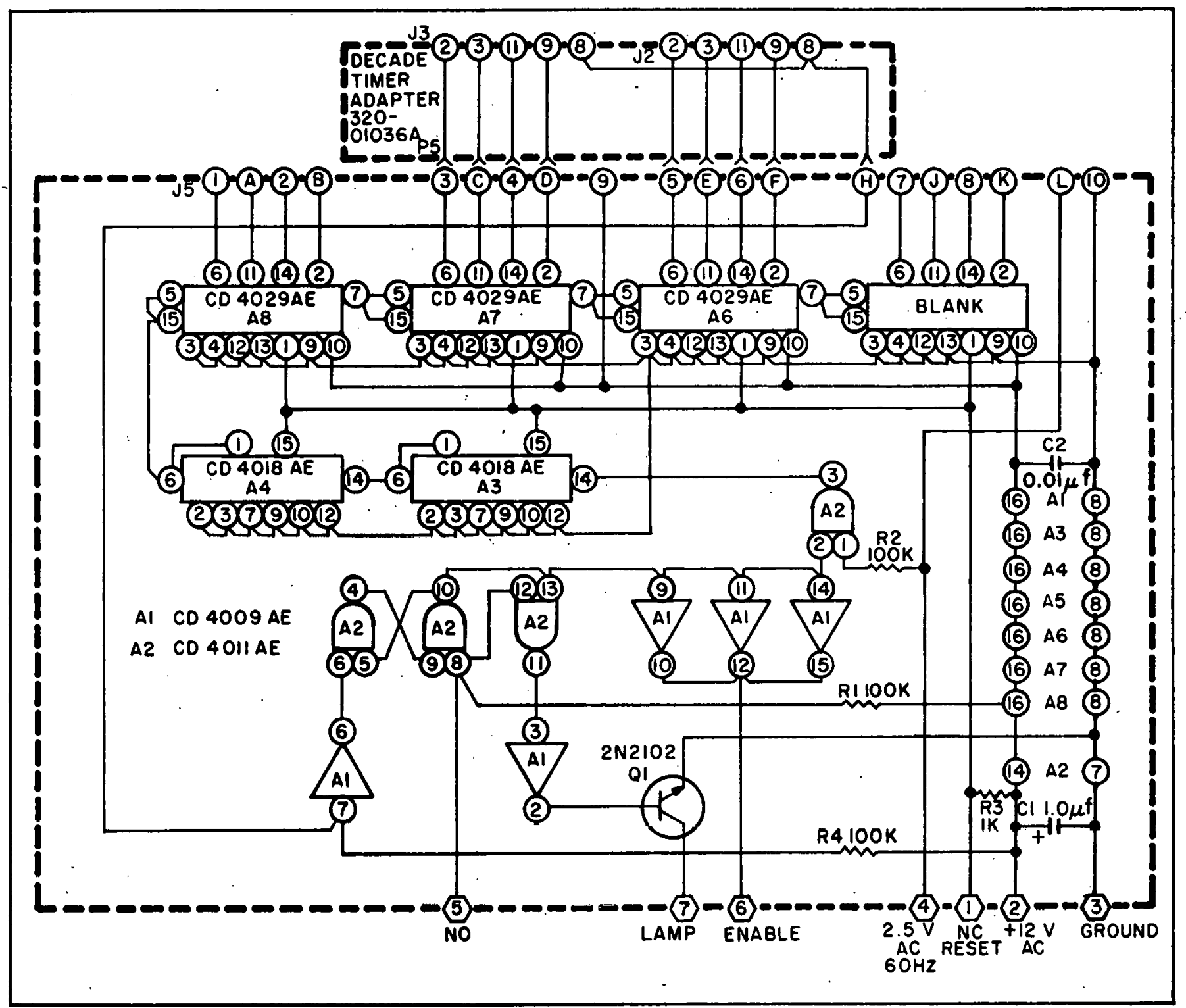

FIGURE 10. Timer Printed Circuit Board of Model C (27.213-23). 
RFP-2301

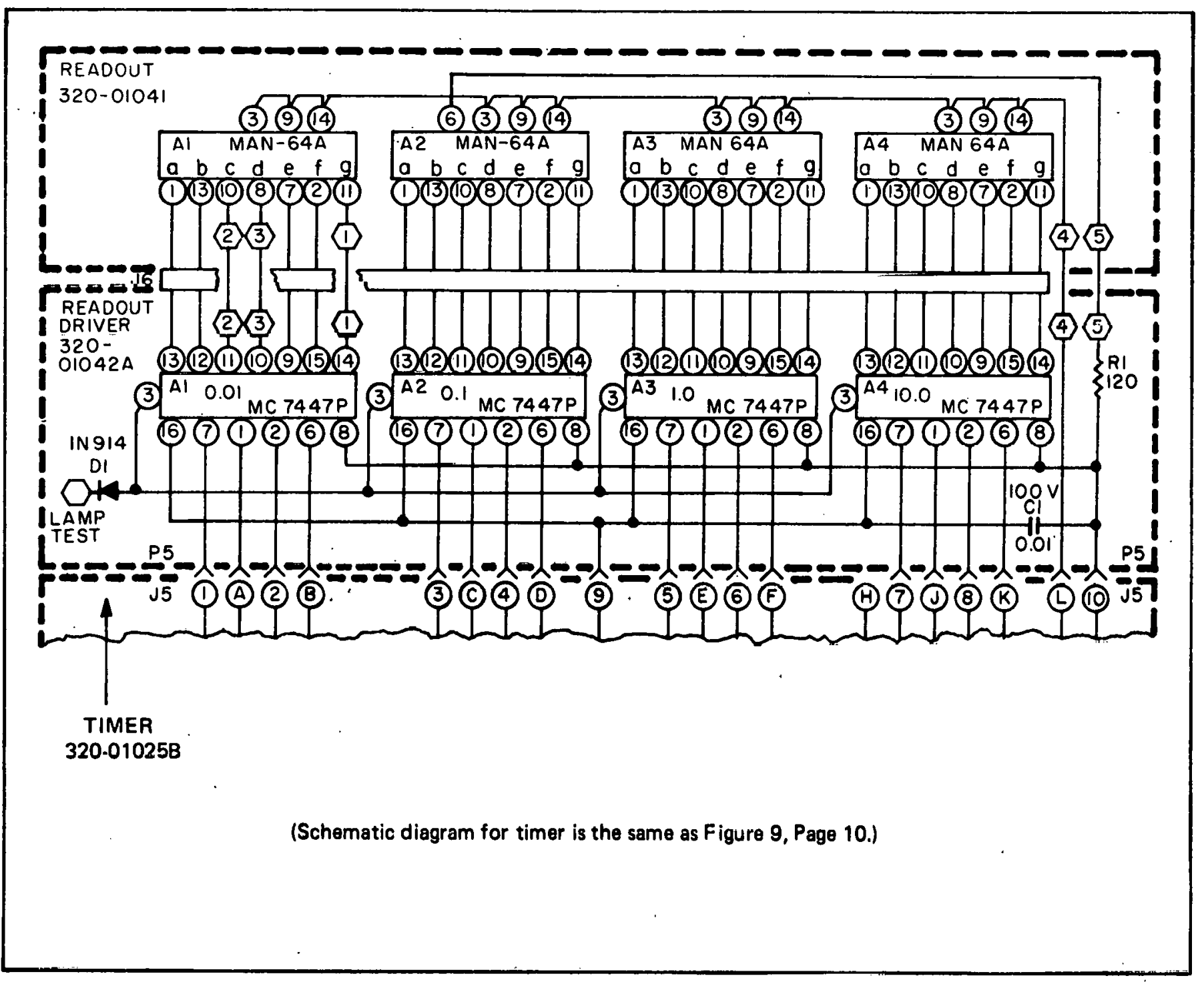

FIGURE 11. Schematic of Readout and Driver for Model B (27213-21). 


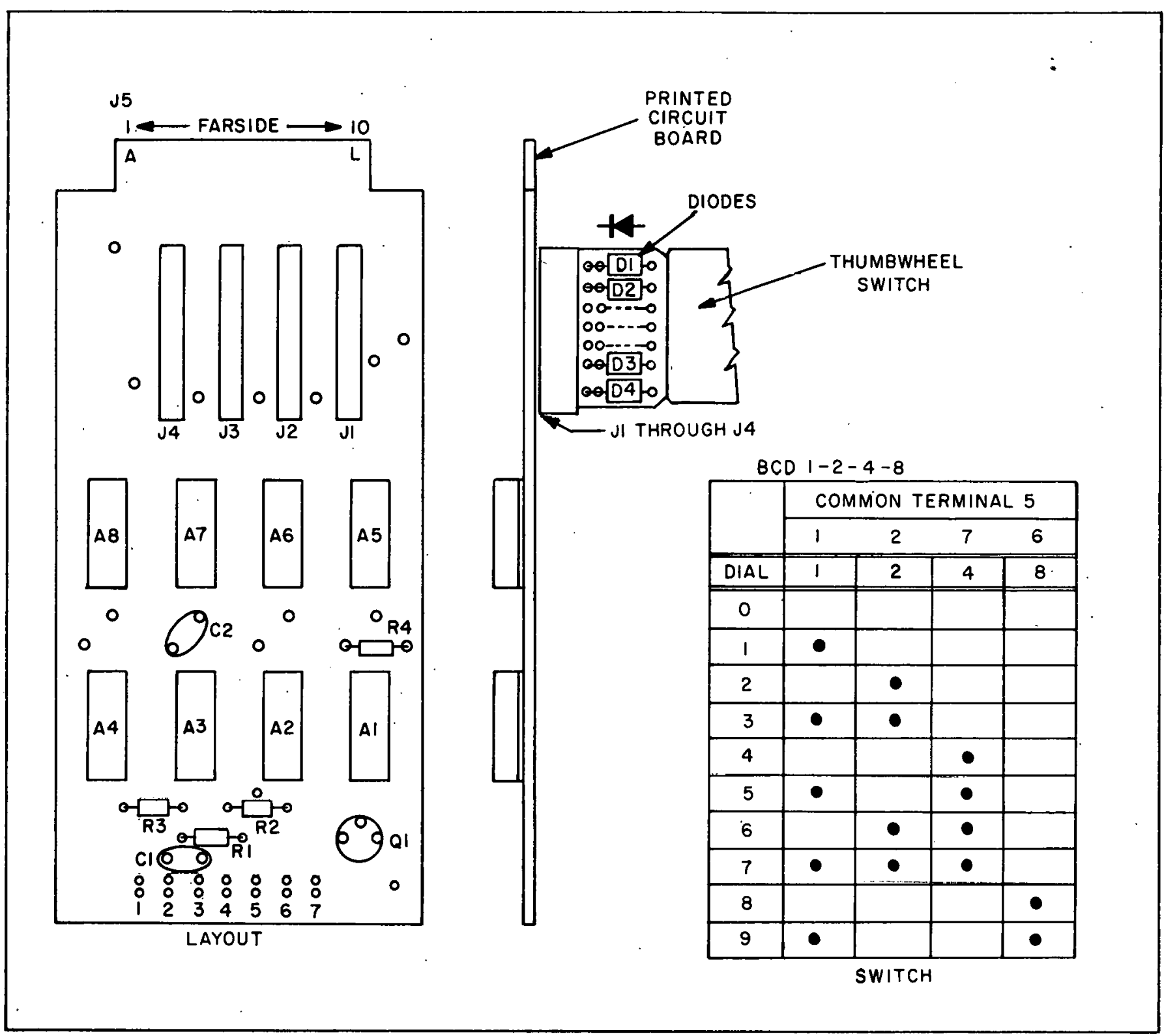

FIGURE 12. Component Layout and Switch Data for Model A (24370-21). 


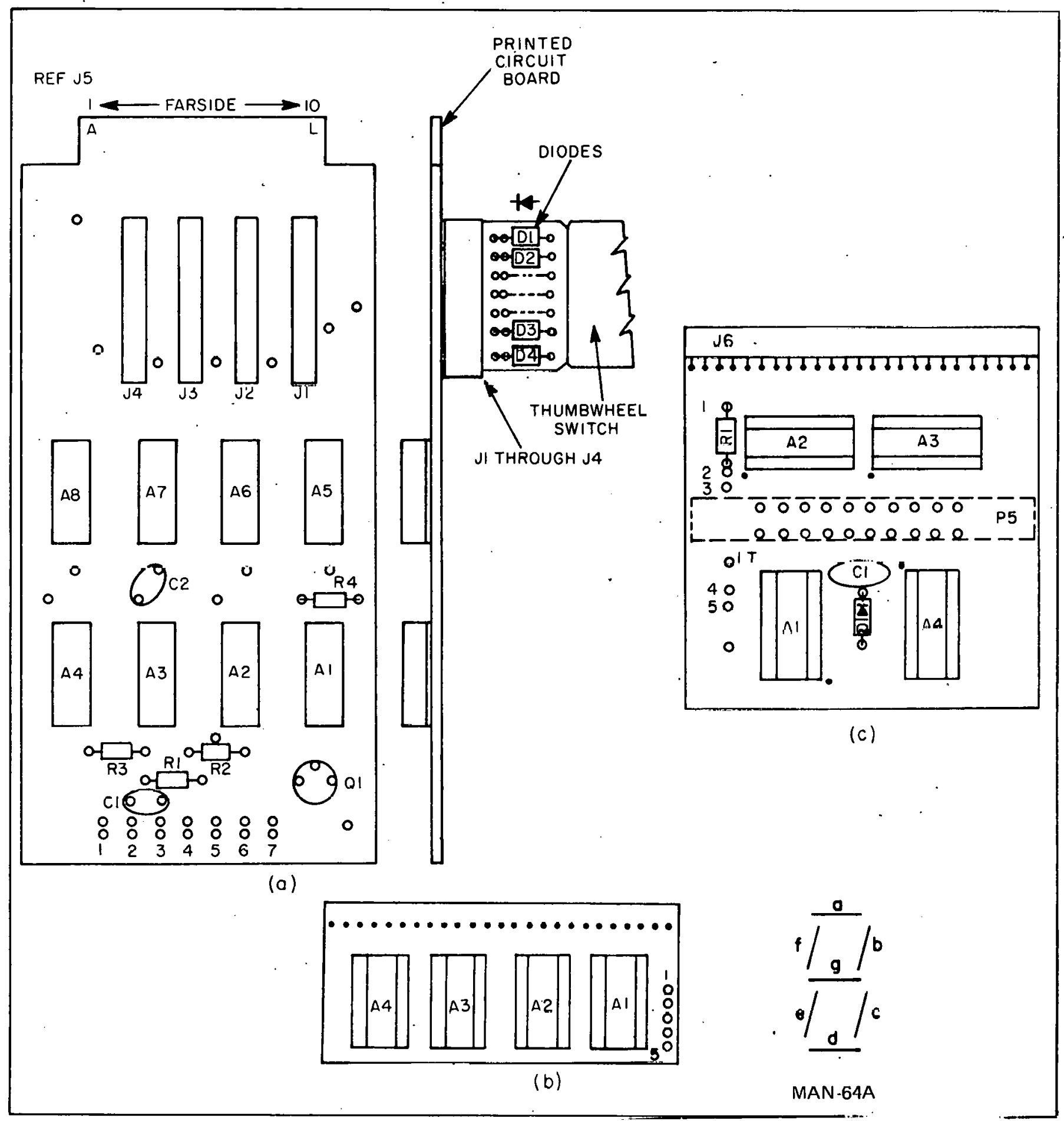

FIGURE 13 (a), (b), and (c). Component Layout for Model B (27213-21) is . shown in (a); Readout Components (b); and Readout Driver Components (c). 


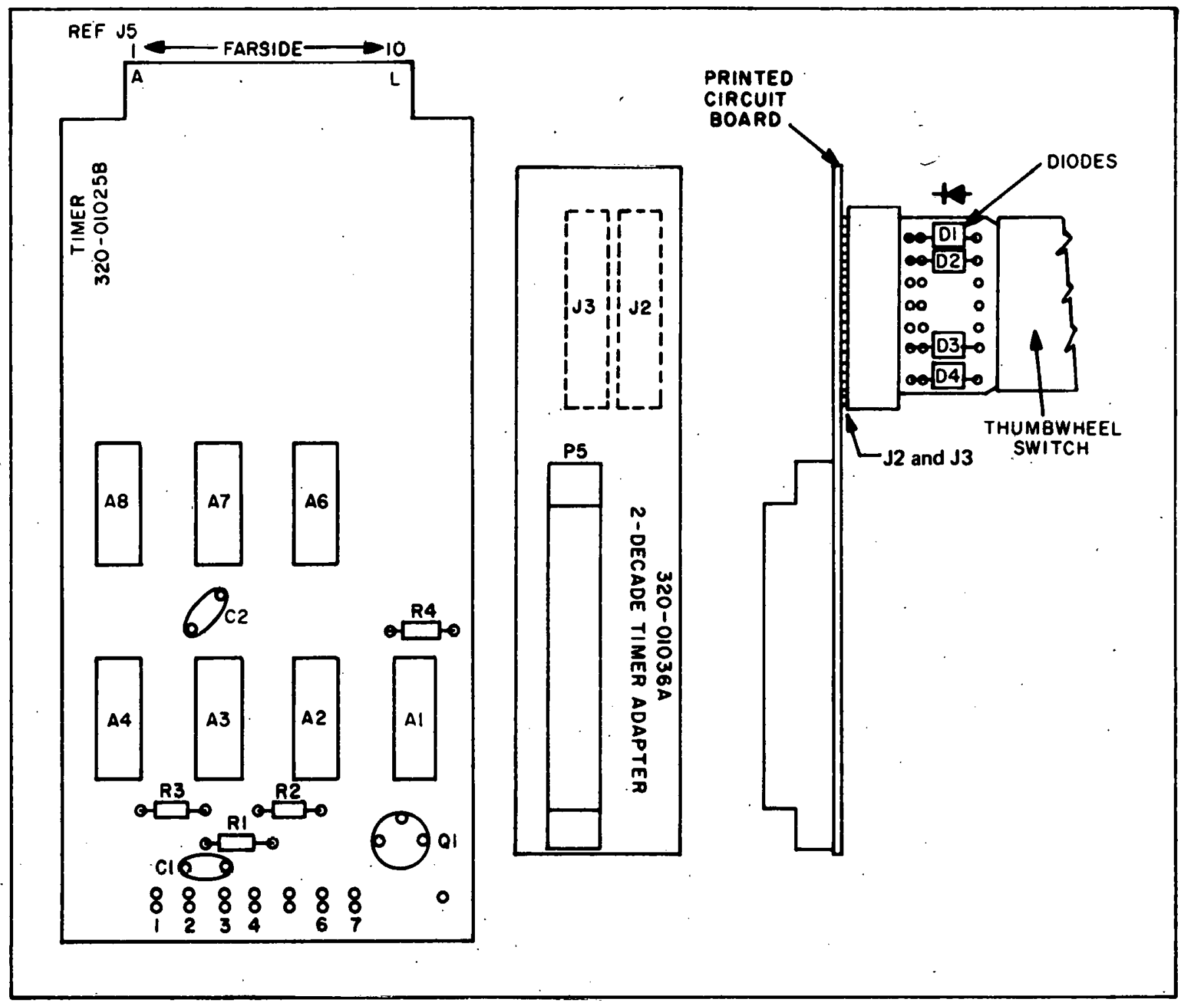

FIGURE 14. Adapter Component Layout for Model C. (27213-23). 
RFP-2301 